\title{
FLUXUS E ARTE POSTAL COMO ARTE RELACIONAL: Breve estudo
}

\author{
Isadora Banducci Amizo 1
}

isadorabanducci@hotmail.com

\section{Resumo}

Este artigo tem como objetivo a análise das questões que envolvem a produção da Arte postal ou Mail art, e do grupo Fluxus, difundidas ao redor do mundo a partir da década de 1960. Procura-se investigar sua aproximação com o conceito de arte relacional, exposto pelo crítico e filósofo francês Nicolas Bourriaud no livro "Estética relacional". Para isso, são revisadas algumas das temáticas que envolvem as duas expressões artísticas destacando-se a produção de alguns de seus principais expoentes.

Palavras-chave: arte postal, arte relacional, Nicolas Bourriaud, Fluxus, Paulo Bruscky.

\section{Abstract}

This article aims to analyze the issues surrounding the production of the Mail Art and Fluxus, disseminated around the world from the 1960s. It pretends to investigate their approach to the concept of relational art, exposed by the critic and French philosopher Nicolas Bourriaud in his book "Relational Aesthetics". For this, some of the themes involving the two artistic expressions are reviewed emphasizing the production of some of its leading exponents.

Keywords: mail art, relational art, Nicolas Bourriaud, Fluxus, Paulo Bruscky.

Em "Estética relacional" 2, publicado pela primeira vez em 1998, o crítico e curador francês Nicolas Bourriaud investiga os interesses da arte dos anos 1990, suas relações com a sociedade, a história e a cultura. Analisando obras de artistas contemporâneos ${ }^{3}$, como Rirkrit Tiravanija e Maurizio Cattelan, entre outros, identifica linhas comuns que se estabelecem em suas concepções, voltadas ao convívio e às relações.

Partindo da noção de que os vínculos sociais tornaram-se um produto padronizado e controlado pelas grandes vias da comunicação - que reduzem as possibilidades de interação

\footnotetext{
${ }^{1}$ Mestranda em Arquitetura e Urbanismo - PPG-FAU-UnB

${ }^{2}$ Versão do original "Esthétique relationelle”, traduzida para o português.

3 Os termos "contemporâneo" e "arte contemporânea" são utilizados aqui para fazer referência à produção da década de 1990, período de elaboração e publicação da obra “Estética Relacional”.
} 
humana-, Bourriaud aponta a nova prática artística como um contraponto, um campo fértil de experimentações sociais, parcialmente poupado da uniformização dos comportamentos, às quais associa a ideia de uma arte relacional (BOURRIAUD, 2009).

O autor afirma que a atividade artística constitui um jogo cujas formas e funções evoluem conforme as épocas e contextos sociais e que, por isso, deve ser estudada no presente. No entanto, para entender as produções do período em questão, apoia-se, paralelamente, na história da arte dos anos pós-1960.

Bourriaud defende a ideia de que a arte relacional toma a esfera das interações humanas e seu contexto social como horizonte teórico, como alternativa às restrições ideológicas geradas pela comunicação em massa. Trata-se, para ele, de uma forma de arte cuja essência é dada pela intersubjetividade e que tem o encontro como tema central (BOURRIAUD, 2009).

Entende-se que há, dessa forma, uma valorização do intercâmbio humano, de forma independente às "zonas de comunicação" tradicionais impostas aos indivíduos. Para Bourriaud,

A essência da prática artística residiria, assim, na invenção de relações entre sujeitos; cada obra de arte particular seria a proposta de habitar um mundo em comum, enquanto o trabalho de cada artista comporia um feixe de relações com o mundo, que geraria outras relações, e assim, até o infinito. (BOURRIAUD, 2009, p.31)

Partindo-se, então, dessa concepção da arte contemporânea - dentro da ótica relacional -, pressupõe-se a possibilidade de traçar, aqui, uma aproximação desses conceitos à produção da "Arte postal", também chamada de "Mail art", difundida a partir da década de 1960.

Para isso, é assumida a compreensão de que os movimentos anteriores à arte contemporânea exerceram, de alguma forma, influência sobre suas concepções, e da defesa do próprio autor de que "a arte sempre foi relacional em diferentes graus, ou seja, fator de socialidade e fundadora de um diálogo" (BOURRIAUD, 2009, p.21).

\footnotetext{
${ }^{4}$ Utiliza-se, também, o termo "arte correio" para definir a mesma expressão artística.
} 
A arte postal foi - e ainda é, considerando-se algumas manifestações pontuais recentes - uma rede internacional que se utilizou da troca de correspondências entre seus membros através do correio, para, essencialmente, disseminar um material artístico. Como objeto de intervenção, alguns artistas utilizavam os próprios envelopes postais, com colagens, pinturas, gravuras, fotografias e textos, ou enviavam dentro dele o conteúdo das criações.

Apesar da prática da troca postal já circundar experiências aproximadas de artistas anteriores - como os futuristas, dadaístas e surrealistas-, que, além de precedentes da expressão, foram influentes no novo modo de pensar e agir sobre a arte em geral-, seu grande ápice se dá entre as décadas de 1960 e 1980.

Assume-se como marco inicial dessa arte, a criação da "New York Correspondance School of Art", em Nova York, por volta de 1963. Tratava-se de uma escola sem fins lucrativos, criada pelo artista neodadaísta americano Ray Johnson, através da qual se oficializava o princípio da prática das trocas. Ray Johnson foi um dos principais expoentes da arte postal, que se tornou mundialmente conhecida como "Mail Art", devido a ele. De acordo com Fabiane Pianowski, o termo "correspondance", que intitula a escola, vem de uma sugestão de Ray Johnson em fazer uma associação com as palavras "dança" e "dançar", do inglês "dance", salientando, assim, o entrelaçamento das relações sugerido pelas trocas postais (PIANOWSKI, 2013).

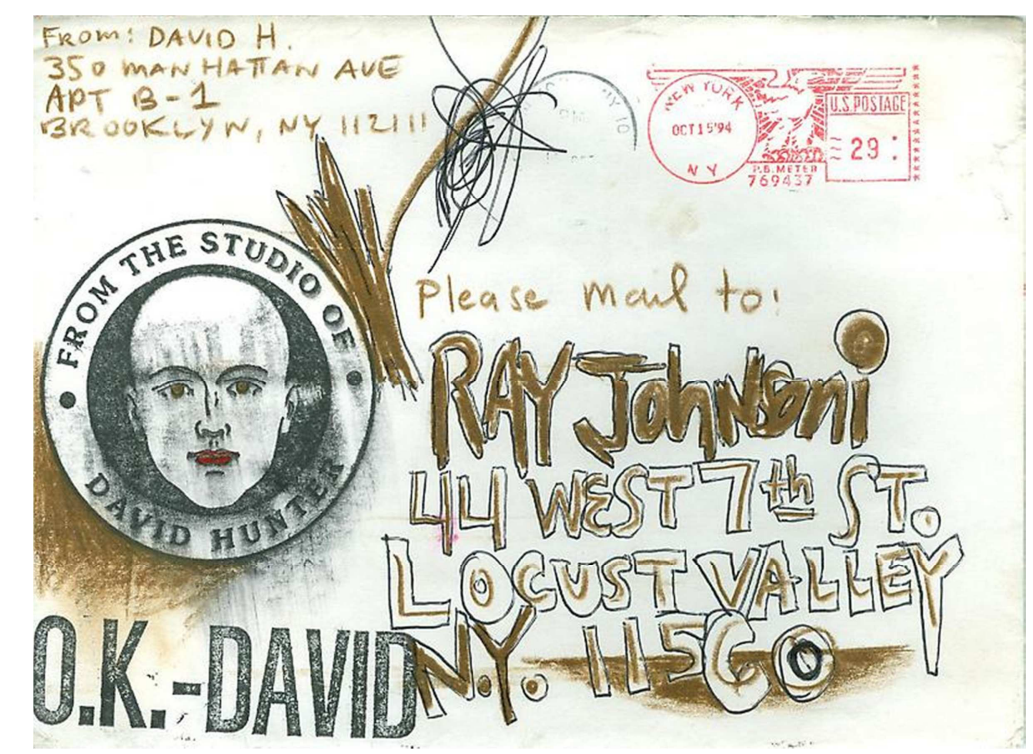

Figura 1 - Envelope enviado por David Hunter e remetido à Ray Johnson.

Fonte: Ray Johnson. Disponível em: 〈rayjohnsonestate.com〉. Acesso em: Nov/2013. 
É, no entanto, atribuído ao grupo Fluxus, o papel de grande propulsor do movimento em rede mundial, que concretizou a nova forma de produção artística. Fluxus foi um movimento internacional de artistas, cujos trabalhos se desenvolveram mais fortemente durante as décadas de 1960 e 1970 e que, para além da arte postal, atuaram na criação de trabalhos multimídia, performances e outras redes.

Seu principal dirigente foi o artista lituano George Maciunas, que através desse grupo, se mobilizava para mudar a forma de pensar o mundo. Thomas Kellein, referindo-se à postura de Maciunas tanto às obras tangíveis quanto às performances, afirma que o artista "(...) se ocupava de conseguir materiais, projetar e imprimir cartões com títulos ou partituras, de se corresponder com os artistas (a ponto de ter ideias por eles), de projetar uma etiqueta para o nome de cada artista e de distribuir mercadorias" (KELLEIN, 2002, p.52).

Conforme Jon Hendricks, o Fluxus "teve Maciunas como seu pai, e como mãe sua rejeição dos valores e do meio acerca das 'Artes Eruditas' e a comercialidade que dominou o mercado internacional de arte após o fim da Segunda Guerra Mundial" (HENDRICKS, 2002, p. 14).

O grupo impactou as artes do período, bem como a produção artística posterior, com seu caráter radical e de ruptura. Conforme Cristina Freire, "o efêmero das ações Fluxus misturava arte e cotidiano, buscava destruir convenções e valorizar a criação coletiva de artistas, músicos e escritores" (FREIRE, 2006, p.15). Esses artistas questionavam, essencialmente, a linha divisória existente entre as obras de arte e o resto das coisas, rompendo com as definições anteriores que as consideravam em termos de Arte Erudita, separadas do fluxo da vida. Arthur Danto aponta que, através das ideias do Fluxus, Maciunas tentava dizer que algo poderia ser arte sem necessariamente ser Arte Erudita, revelando, então, que o próprio cotidiano poderia ser maravilhoso o bastante (DANTO, 2002).

Ainda de acordo com Danto, "o que era característico da arte Fluxus era que grande parte dela seria captada por qualquer pessoa versada em História da Arte como não sendo arte de maneira alguma" (DANTO, 2002, p.26). O que se demonstrava com isso é que qualquer definição existente da arte deveria lidar com objetos e ações pouco atraentes.

Essas questões e fundamentos aparecem nas obras do artista multimídia pernambucano Paulo Bruscky, um dos representantes da arte postal no Brasil e um grande incentivador dessa 
prática. Evidenciaram-se, talvez mais nitidamente, em questionamentos como "O que é arte? Para que serve?", que marcaram uma das performances do artista.

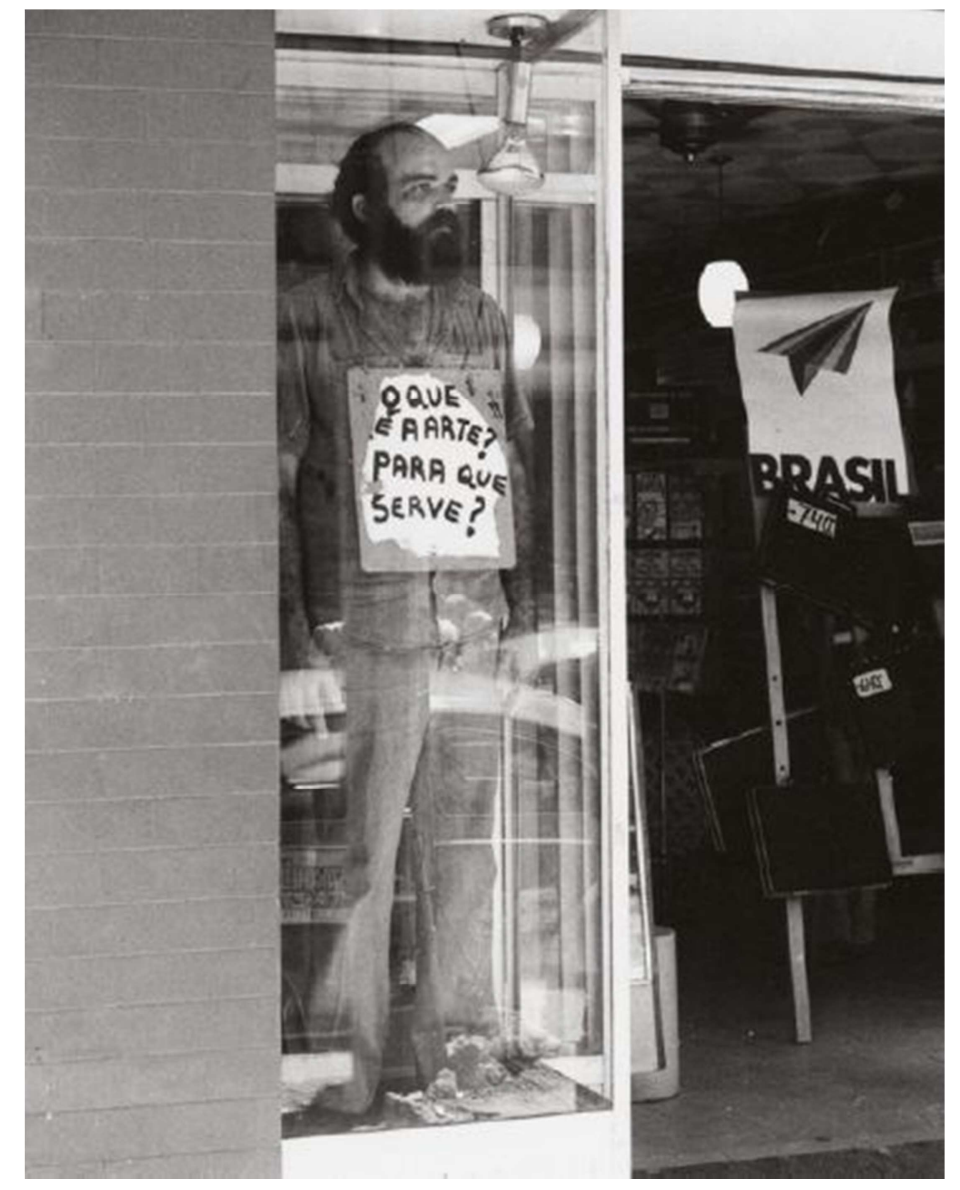

Figure 2- O artista Paulo Bruscky em performance intitulada "O que é arte? Para que serve”, de 1978, em Recife. Fonte: BOMB Magazine. Disponível em: < http://bombmagazine.org/article/7335/paulo-bruscky> Acesso em: nov/2013.

Bruscky ingressou no movimento internacional das correspondências, estabelecendo trocas com os membros do grupo Fluxus em meados da década de 1970. Defende, seguindo a direção do Fluxus, como um dos preceitos fundamentais de sua obra a não dissociação entre arte e vida, uma característica que se reconhece também na arte postal em geral - que dentro de sua proposta questiona a diferenciação e os limites entre uma e outra - e sobre a qual se fundamenta, da mesma forma, a essência da arte relacional.

Além do Brasil, a arte postal manifestou-se também em outros países da América Latina como Uruguai, Argentina e Chile, mais significativamente a partir do final da década de 1960. Nesse período, em que muitos dos países latino-americanos vivenciavam o cenário 
repressor das ditaduras, a arte postal aparecia como um meio alternativo de troca de informações com conteúdos não só artísticos, mas também políticos e de denúncia. Textos e imagens colocados nos envelopes e cartas apontavam as situações de opressão vividas nesses países.

Conforme Pianowisk, "o correio se convertia em um veículo altamente eficaz para a transmissão de mensagens subversivas devido à dificuldade de ter um controle efetivo sobre o enorme fluxo de correspondências enviadas ou recebidas" (PIANOWSKI, 2008, p.58, tradução nossa). As trocas carregavam uma essência política, eram uma tentativa de liberdade, uma forma de resistência - em um momento de repressão-, que se fazia possível diante da impossibilidade de controle.

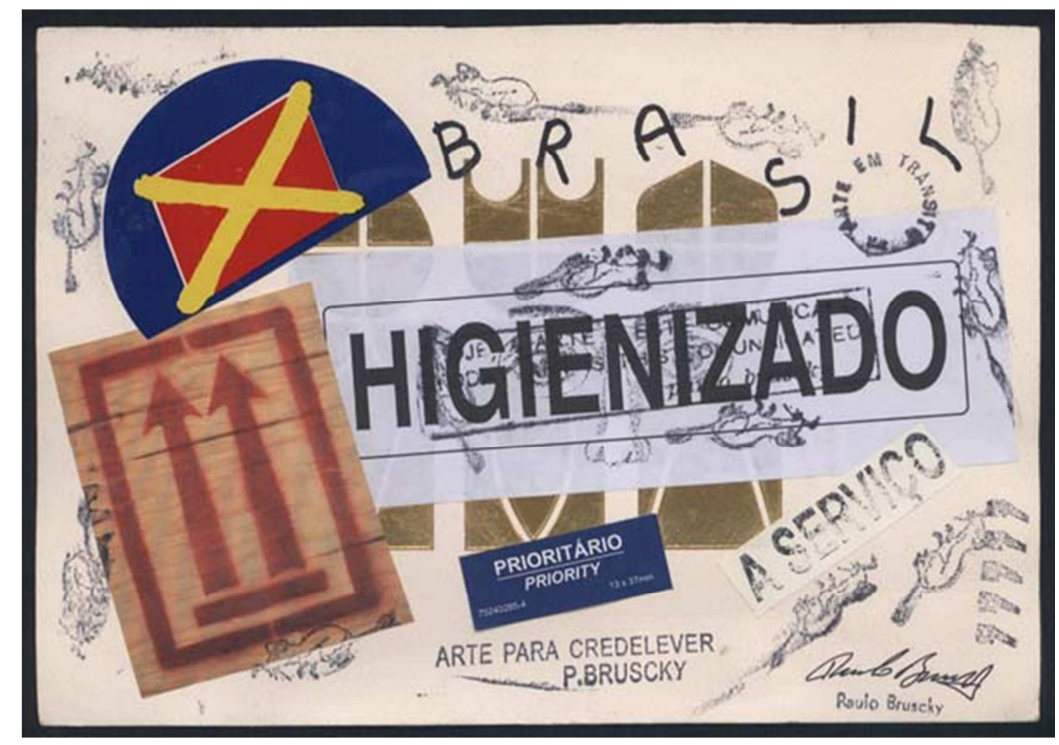

Figura 3 - Obra de Paulo Bruscky.

Fonte: Arte no Modelo. Disponível em: <artenomodelo.blogspot.com>. Acesso em: Nov/2013.

Em seu próprio meio, essa prática artística atingia seu fim. No entanto, o teor subversivo, quando materializado em exposições, levou à censura e prisão de muitos de seus envolvidos, sendo um deles o próprio Bruscky, que viu ser fechada, ainda na abertura, a I Exposição de Arte Postal em Recife, organizada por ele e Daniel Santiago, em 1975.

Bruscky também ficou conhecido por seus questionamentos relativos ao papel da arte e suas formas de seleção e institucionalização. Criticava os espaços fechados dos museus, literal e metaforicamente. Esse aspecto é próprio também da arte postal, já que essa se desenvolve essencialmente fora do espaço controlado das galerias. Isso, porque as trocas de 
correspondências entre os artistas não passavam por qualquer tipo de seleção, repreensão ou premiação.

É válido ressaltar que, apesar dessas trocas acontecerem através de um espaço comum de comunicação, o dos correios, esse é assumido nesse contexto como uma forma alternativa de contato artístico e que, além disso, contém um sentido político. São priorizados, aqui, as relações e o coletivo, correspondendo à ideia de resistência à decomposição do vínculo social, que conforme Bourriaud, é gerada pelos meios de comunicação de massa. Do mesmo modo, da forma como ela se realiza, não são atribuídos valores comerciais à obra, nem se estabelece qualquer tipo de troca mercantil - com exceção do próprio custo da veiculação pelo correio.

Assim, essa prática aproxima-se mais literalmente da ideia de interstício social, que Bourriaud aponta como uma característica da arte relacional, sendo "um espaço de relações humanas que, mesmo inserido de maneira mais ou menos aberta e harmoniosa no sistema global, sugere outras possibilidades de troca além das vigentes nesse sistema" (BOURRIAUD, 2009, p.22).

De forma geral, entende-se que a essência da arte postal se dá na rede de trocas das produções. O produto da atividade artística não consiste apenas no objeto físico materializado; o que se manifesta como expressão artística, de fato, é o intercâmbio gerado e permitido pela comunicação. E é justamente através dela que a proposta se concretiza. Nesse sentido, as práticas da arte postal também dialogam com a arte relacional, à medida que priorizam as relações, não se concentrando na abordagem dos objetos artísticos. Conforme Mônica Zielinski, “(...) não está no objeto (correspondência) a importância, mas no processo como um todo, que envolve as pessoas na circulação do objeto e na discussão dos conceitos que ele contém. A arte não é apenas a correspondência, é todo o processo" (ZIELINSKI, 2004, p.28).

Seria possível dizer, por outro lado, que uma materialização propriamente dita aparece, de certa forma, no registro do resultado, ou nas correspondências enquanto objeto, que, em alguns casos, são posteriormente levadas às exposições de museus e galerias. No entanto, como já ressaltado, essa etapa não compreende substancialmente a obra em si. Além disso, não há um espaço físico concreto para sua manifestação.

Dessa forma, a arte postal estabelece outra proximidade com a arte contemporânea, no que diz respeito ao aspecto da não-disponibilidade, apontado por Bourriaud. $\mathrm{O}$ autor destaca 
que, de maneira distinta à forma mais tradicional do quadro e da escultura - que podem ser observados a qualquer momento, e que se oferecem a um público universal-, a prática artística contemporânea apresenta-se, muitas vezes, num momento determinado e que "uma vez realizada, resta apenas a documentação sobre ela” (BOURRIAUD, 2009, p. 41).

Bourriaud reforça que a arte relacional implica uma espécie de contrato com o observador, uma forma de "combinação". Nesse aspecto, a princípio, há uma distinção das ações que sustentam a arte postal. Isso porque, o membro do grupo, ainda que não atue oficialmente como artista, parece distanciar-se do papel de observador quando participa diretamente das trocas. Entretanto, ainda assim, ambas associam-se dentro dessa perspectiva, considerando-se que a participação e interação dos membros do grupo no movimento da arte postal, em geral, são fundamentais para a sua realização. Cada participante mantém viva a rede, atuando como receptor e criador simultaneamente.

É importante observar também que, no caminho da troca postal entre o remetente e o destinatário, há uma série de personagens envolvidos, que fazem com que sua realização se torne possível. As intervenções nos envelopes, assim como o cartão postal, são abertas e, por isso, expostas às demais pessoas que estabelecem algum tipo de contato com eles. Essas são, portanto, envolvidas com a elaboração e a concretização da obra.

Além disso, conforme aponta Zielinsky,

Ao longo do trajeto, as correspondências podem sofrer modificações, através de contribuições dos artistas que marcam nelas suas posições, acrescentando ou reforçando ideias. Nesse caso, a arte constrói-se no trânsito das mensagens entre os participantes (ZIELINSKY, 2004, p.24).

É, portanto, justamente à ideia do trabalho em rede entre os artistas, e às demais trocas que se estabelecem, que se ressalta a principal convergência com a noção do "relacional", já que uma de suas bases fundamentais é a proposta de novas formas de sociabilidade, formas não convencionais. Ou seja, o grupo dos participantes envolve sua criação como parte de um conjunto social, de tal maneira que o que resulta do trabalho individual é decorrente das experiências desta coletividade. 
Conforme Bourriaud, na arte relacional o artista está interessado em compartilhar sua proposta de produção, envolvendo o espectador na construção da experiência artística, e permitindo assim, que haja uma elaboração coletiva do sentido dessa prática (BOURRIAUD, 2009).

Esse aspecto parece relacionar-se também aos ideais coletivistas que remetem ao Fluxus, sobre os quais Danto chama atenção quando se refere à visão política do movimento. O autor aponta que, na opinião do próprio mentor, Maciunas, o Fluxus era uma coletividade e que "nenhum artista individual, mas apenas a própria coletividade, deve se beneficiar da arte feita em nome do Fluxus" (DANTO, 2002, p.30).

Relações entre sujeitos e coletividade são, portanto, os principais pontos que ligam as expressões da arte postal e do grupo Fluxus - ambos já associados na sua essência - com as definições de Bourriaud para as formas artísticas dos anos de 1990, que convencionou chamar de arte relacional. Isso, mais uma vez, reforça a defesa do autor da ideia de que a arte sempre tenha sido relacional em diferentes aspectos.

Por fim, pode-se dizer que a arte postal como um todo e os artistas nela envolvidos atuaram também na desintegração das barreiras entre as linguagens artísticas e das fronteiras que separavam o mundo. Como não existia um espaço materializado para essas atividades, elas foram precursoras no contato artístico internacional. Apesar de cada participante estar em uma região do mundo, estes se aproximavam através da comunicação, ou seja, das trocas. Nesse sentido, pode-se pensar, ainda, na rede de trocas dessa prática como uma versão introdutória ao cenário vivenciado na contemporaneidade pelos indivíduos do mundo todo através da internet.

\section{REFERÊNCIAS BIBLIOGRÁFICAS}

BOURRIAUD, Nicolas. Estética relacional. Tradução Denise Bottmann. São Paulo: Martins, 2009.

DANTO, Arthur. O mundo como Armazem: Fluxus e Filosofia. In: O que é Fluxus/ O que não é! O porquê. 23-32. The Gilbert and Lila Silverman Fluxus Collection Foundation - Detroit. Brasília / Rio de Janeiro: Centro Cultural Banco do Brasil, 2002. 
FREIRE, Cristina. Arte conceitual. Rio de Janeiro: Jorge Zahar Editor. 2006.

fuseaction=istas_biografia\&cd_verbete=2995 >. Acesso em: 24.out.2013.

HENDRICKS, Jon. O que é Fluxus? O que não é! O porquê. In: O que é Fluxus? O que não é! O porquê. 14-15. The Gilbert and Lila Silverman Fluxus Collection Foundation - Detroit. Brasília / Rio de Janeiro: Centro Cultural Banco do Brasil, 2002.

ITAUCULTURAL. Paulo Bruscky (1949). Enciclopédia Itaú Cultural. Artes Visuais. Disponível em: < http://www.itaucultural.org.br/aplicexternas/enciclopedia_ic/index.cfm?-

KELLEIN, Thomas. Fluxus: “Acabamos sendo um bando de palhaços”. In: O que é Fluxus? O que não é! O porquê. 51-54. The Gilbert and Lila Silverman Fluxus Collection Foundation - Detroit. Brasília / Rio de Janeiro: Centro Cultural Banco do Brasil, 2002.

LUSTOSA, Fernando. Entrevista com Paulo Bruscky. DASartes 15. 2012. Disponível em: http://dasartes.com/2012/entrevista-com-paulo-bruscky/.Acesso em: 26 out.2013

PIANOWSKI, Fabiane. Arte correo. La red fuera de control. Disponível em: <http://www.artyarqdigital.com >. Acesso em: 18 nov.2013.

PIANOWSKI, Fabiane. Arte postal. Merzmail. Disponível em: <http://www.merzmail.net/arteposta larte.htm>. Acesso em: 24 out.2013.

REBOUÇAS, Fernando. Arte Postal. Infoescola. Disponível em: <http://www.infoescola.com/artes/arte-postal/>. Acesso em: 24 out.2013.

ZIELINSKY, Mônica. Todo lugar é possível. A rede de arte postal, anos 70 e 80 . Dissertação de mestrado. UFRGS. Porto Alegre, 2004. 